\title{
p53-independent upregulation of miR-34a during oncogene-induced senescence represses MYC
}

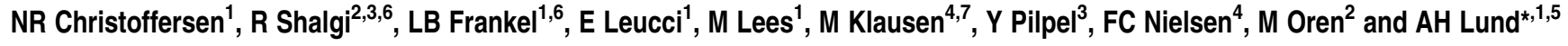

\begin{abstract}
Aberrant oncogene activation induces cellular senescence, an irreversible growth arrest that acts as a barrier against tumorigenesis. To identify microRNAs (miRNAs) involved in oncogene-induced senescence, we examined the expression of miRNAs in primary human TIG3 fibroblasts after constitutive activation of B-RAF. Among the regulated miRNAs, both miR-34a and miR-146a were strongly induced during senescence. Although members of the miR-34 family are known to be transcriptionally regulated by $\mathrm{p} 53$, we find that miR-34a is regulated independently of $\mathrm{p} 53$ during oncogene-induced senescence. Instead, upregulation of miR-34a is mediated by the ETS family transcription factor, ELK1. During senescence, miR-34a targets the important proto-oncogene MYC and our data suggest that miR-34a thereby coordinately controls a set of cell cycle regulators. Hence, in addition to its integration in the p53 pathway, we show that alternative cancer-related pathways regulate miR-34a, emphasising its significance as a tumour suppressor.
\end{abstract}

Cell Death and Differentiation (2010) 17, 236-245; doi:10.1038/cdd.2009.109; published online 21 August 2009

Senescence is a cellular stress response that results in a permanent proliferative arrest of the cell. The term cellular senescence was originally used to describe the limited proliferative potential of cultured cells, caused by the gradual shortening of telomeres with each round of replication, leading to the activation of the DNA double-strand break checkpoint. ${ }^{1-3}$ During the last decade it has become evident that cellular senescence can occur in a number of situations that do not involve telomere dysfunction, including DNA-replicatory stress, oncogene activation and oxidative stress.

Oncogene-induced senescence was first reported as a result of constitutive activation of RAS in primary cells. ${ }^{4}$ After an initial proliferative burst, cells become growth arrested and display morphological changes associated with cellular senescence, accompanied by the upregulation of $\mathrm{p} 14^{\mathrm{ARF}}$ / $\mathrm{p} 19^{\mathrm{ARF}}$ and $\mathrm{p} 16^{\mathrm{INK} 4 \mathrm{a}} .{ }^{5}$ The physiological relevance of this phenomenon has been questioned, but recently, in vivo induction of senescence has been shown for a number of oncogenes, ${ }^{6,7}$ including $B-R A F$ in human benign tumours and $\mathrm{N}$-RAS, K-RAS, H-RAS, B-RAF and E2F3 in mouse models. In vivo senescence has also been reported as a consequence of tumour suppressor inactivation for PTEN and NF1 in human benign tumours, and it has been shown that restoration of functional p53 leads to senescence, which prevents tumour progression in vivo. ${ }^{6,7}$ From these reports, it is evident that oncogene-induced senescence constitutes a barrier against tumorigenesis. Oncogenes that elicit a senescence response often converge on the activation of p53 and/or RB, ${ }^{7-9}$ although
RAF-induced senescence independent of both p53 and RB has been reported in human cells. ${ }^{10}$ The capacity of different oncogenes to trigger senescence seems to depend on cell and tissue type, perhaps reflecting the integrity of tumour suppressor networks. In human fibroblasts, inactivation of neither p53 nor RB alone overcomes RAS-induced senescence, whereas simultaneous inactivation of both pathways does. ${ }^{4}$ It is therefore important to identify additional molecular mechanisms involved in senescence.

MicroRNAs (miRNAs) are important regulators of gene expression and they are involved in virtually all cellular processes, including proliferation, differentiation, metastasis and apoptosis. ${ }^{11}$ Accordingly, it has been shown that some miRNAs may be categorised as bona fide tumour suppressors or proto-oncogenes. ${ }^{12}$ In this study, we investigate the involvement of miRNAs in oncogene-induced senescence. To address this issue, we identified differentially regulated miRNAs in human diploid fibroblasts undergoing oncogeneinduced senescence. We report a strong upregulation of miR-34a during B-RAF-induced senescence. The miR-34 family members $(a, b$ and $c)$ have attracted much attention because of their identification as p53 target genes and their reported involvement in p53-mediated processes, such as cell cycle arrest and apoptosis. ${ }^{13-18}$ We show that miR-34a upregulation during B-RAF-induced senescence is independent of p53. Rather, the regulation is mediated by ELK1, a previously unreported regulator of miR-34a transcription belonging to the ETS family of transcription factors. Furthermore, we find that

\footnotetext{
${ }^{1}$ Biotech Research \& Innovation Centre, University of Copenhagen, Copenhagen, Denmark; '²Department of Molecular Cell Biology, the Weizmann Institute, Rehovot, Israel; ${ }^{3}$ Department of Molecular Genetics, the Weizmann Institute, Rehovot, Israel; ${ }^{4}$ Department of Clinical Biochemistry, Copenhagen University Hospital, Copenhagen, Denmark and ${ }^{5}$ Center for Epigenetics, University of Copenhagen, Copenhagen, Denmark

${ }^{*}$ Corresponding author: AH Lund, Biotech Research \& Innovation Centre, University of Copenhagen, Ole Maaløes Vej 5, DK-2200 Copenhagen, Denmark.

Tel: + 45353256 57; Fax: + 45353256 69; E-mail: anders.lund@ bric.dk

${ }^{6}$ These authors contributed equally to this work.

${ }^{7}$ Current address: Novozymes A/S, Krogshoejvej 36, DK-2880 Bagsvaerd, Denmark

Keywords: miRNA; miR-34a; B-RAF; senescence; MYC

Abbreviations: 4-OHT, 4-hydroxytamoxifen; 4-tU, 4-thiouridine; 5-FU, 5-fluorouracil; ChIP, chromatin immunoprecipitation; EtOH, ethanol; miRNA, microRNA; PI, propidium iodide; SA- $\beta$-gal, senescence-associated beta-galactosidase

Received 17.2.09; revised 07.7.09; accepted 09.7.09; Edited by G Melino; published online 21.8.09
} 
miR-34a targets the important proto-oncogene MYC during B-RAF-induced senescence, suggesting that miR-34a through $M Y C$ repression mediates indirect downregulation of an entire set of mitotic genes during B-RAF-induced senescence.

\section{Results}

B-RAF oncogene activation regulates miRNAs. To identify miRNAs involved in oncogene-induced senescence, we examined the expression of miRNAs in hTERT-immortalised TIG3 TERT/AB-RAF:ER cells stably expressing a conditional BRAF construct, $\triangle \mathrm{B}-\mathrm{RAF}: \mathrm{ER}{ }^{19}$ In human fibroblasts, $\triangle \mathrm{RAF}-1$ :ER induces irreversible cellular senescence through activation of the MAP-kinase pathway, which is accompanied by increased levels of $\mathrm{p} 16^{\mathrm{INK} 4 \mathrm{a}}$ but does not depend on p53 and p21. ${ }^{20}$ In accordance with a senescent phenotype, TIG3 TERT/DBRAF:ER cells become senescent within 3-5 days of B-RAF activation (through treatment with $500 \mathrm{nM}$ 4-hydroxytamoxifen, 4-OHT), as assessed by morphological changes, stalled growth, increased senescence-associated beta-galactosidase (SA- $\beta$-gal) activity, formation of senescence-associated heterochromatic foci (data not shown) and gradually increased expression of p16 ${ }^{\text {INK4a }}$ (Supplementary Figure S1).

We arrayed miRNA expression in normal versus senescent TIG3 TERT/DB-RAF:ER cells after 3 days of B-RAF activation. Eighteen miRNAs were significantly regulated across four biological replicates $(P<0.001$, Table 1$)$. The results were validated for miR-146a and miR-34a that were most prominently regulated (Figure 1). The absolute levels of miR146a were low (Supplementary Figure S2), which prompted us to focus on miR-34a, which was approximately eightfold upregulated after 3 days of B-RAF activation (Table 1). The family members miR-34b and $-34 c$ were not detected on the arrays and their lack of expression was validated by quantitative PCR (qPCR) (data not shown).

Table 1 Differentially expressed miRNAs in TIG3 TERT/AB-RAF:ER cells undergoing senescence (OIS) versus normal cells

\begin{tabular}{rlrr}
\hline & Unique ID & OIS/normal & $P$-value \\
\hline 1 & hsa-miR-146a & 11.27 & $<0.0001$ \\
2 & hsa-miR-34a & 8.85 & $<0.0001$ \\
3 & hsa-miR-29b & 3.23 & $<0.0001$ \\
4 & hsa-miR-31 & 3.09 & $<0.0001$ \\
5 & hsa-miR-154* & 3.03 & $<0.0001$ \\
6 & hsa-miR-532 & 2.93 & $<0.0001$ \\
7 & hsa-miR-376b & 2.91 & 0.0001 \\
8 & hsa-miR-132 & 2.76 & 0.0001 \\
9 & hsa-miR-376a & 2.69 & $<0.0001$ \\
10 & hsa-miR-425-5p & 2.22 & 0.0005 \\
11 & hsa-miR-495 & 2.07 & 0.0008 \\
12 & hsa-miR-660 & 2.05 & 0.0009 \\
13 & hsa-miR-27b & 0.33 & 0.0001 \\
14 & hsa-miR-193b & 0.34 & $<0.0001$ \\
15 & hsa-miR-335 & 0.45 & 0.0005 \\
16 & hsa-miR-765 & 0.56 & 0.0001 \\
17 & hsa-miR-30a-3p & 0.59 & 0.0006 \\
18 & hsa-miR-421 & 0.71 &
\end{tabular}

*Shown is the mean fold change of four biological replicates and the corresponding $P$-value
Cellular effects of miR-34a. To characterise the cellular effects of miR-34a, we transfected TIG3 TERT/DB-RAF:ER cells with a miR-34a precursor and analysed the effect on cellular morphology, growth and cell cycle progression. Cells overexpressing miR-34a exhibited a senescence-like morphology (Supplementary Figure S3). In accordance with previous studies in primary cell cultures, ${ }^{17}$ overexpression of miR-34a reduced cellular proliferation (Figure $2 \mathrm{a}$ ), resulting from an accumulation of cells in the G1 phase of the cell cycle and concomitant reductions of the cell populations in $\mathrm{S}$ and G2/M phases (Figure 2b).

p53-independent regulation of miR-34a. Members of the miR-34 family are direct transcriptional targets of $\mathrm{p53}$, and the miR-34 gene promoters contain p53-binding sites that are conserved among humans and rodents. ${ }^{13,14,16-18}$ Several studies have shown p53-dependent upregulation of miR-34a in human and mouse cells, as well as in mouse models, as a consequence of DNA damage. ${ }^{13,14,16-18,21}$ To assess the importance of p53 for miR-34a regulation during B-RAF-induced senescence, we depleted p53 in TIG3 TERT/ $\triangle \mathrm{B}-\mathrm{RAF}$ :ER cells using siRNA. Surprisingly, although p53 depletion resulted in a moderate decrease in the level of miR-34a in normal cells, it had little effect on the degree of miR-34a upregulation after B-RAF activation (Figure 3a). Efficient p53 knockdown was verified by western blotting (Figure $3 b$ ). In addition, p53 knockdown prevented the induction of p53 and its target gene, p21, after treatment of the cells with the DNA damage-inducing agent 5-fluorouracil (5-FU) (Supplementary Figure S4a). To further verify the p53-independent regulation of miR-34a during B-RAFinduced senescence, we produced TIG3 TERT/AB-RAF:ER cells with stable expression of p53DD, a dominant-negative

a
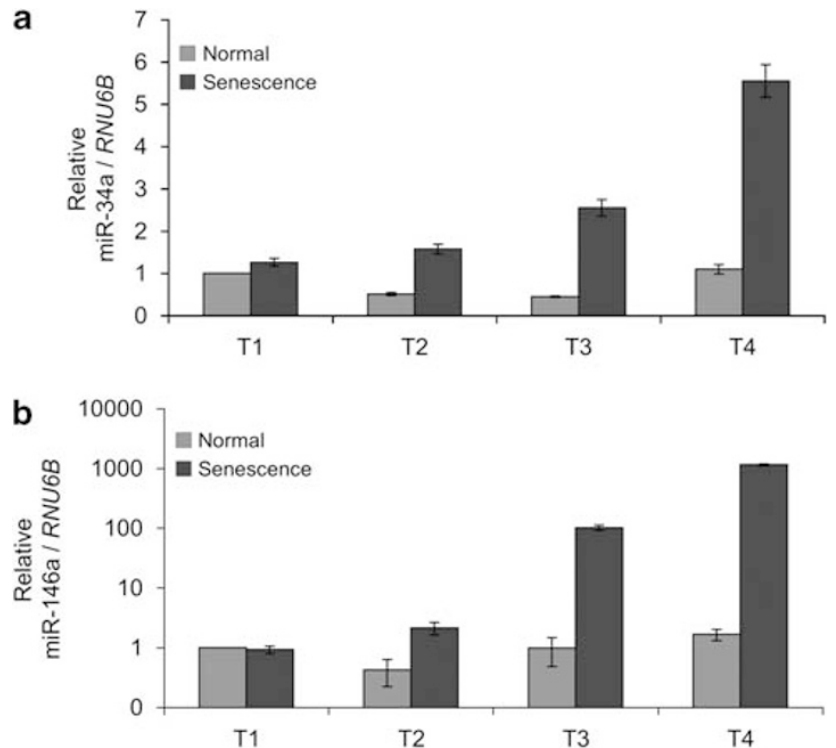

Figure 1 Validation of miRNA microarray data by qPCR. (a and $\mathbf{b})$ Regulation of miR-34a and miR-146a in TIG3 TERT/B-RAF:ER cells on days 1-4 (T1-T4) after inducing senescence by B-RAF activation. Values are normalised to RNU6B levels and shown relative to $\mathrm{T} 1$ in normal cells. Data are shown as the mean \pm S.D. of three replicates 

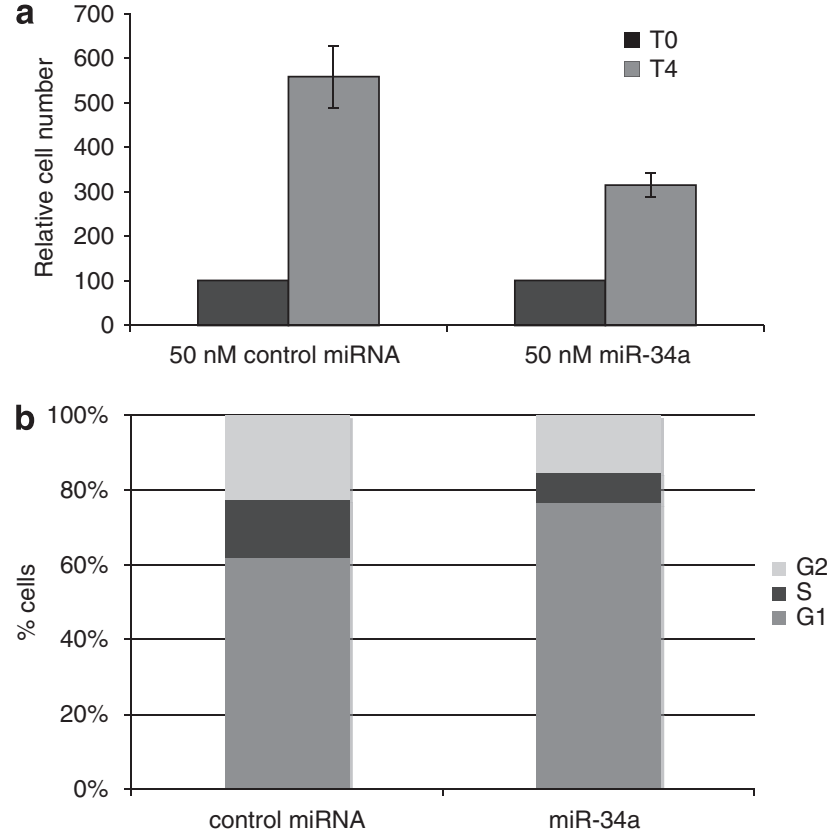

Figure 2 miR-34a inhibits growth of TIG3 TERT/B-RAF:ER cells. (a) Four-day growth assay of cells transfected with $50 \mathrm{nM}$ miR-34a or a control miRNA. Cell number is shown relative to T0. Data are shown as the mean \pm S.D. of three replicates and is representative of three independent experiments. (b) miR-34a affects cell cycle in TIG3 TERT/B-RAF:ER cells. Cell cycle analysis of cells 3 days after transfection with $50 \mathrm{nM}$ miR-34a or a control miRNA. A representative experiment is shown

variant of the $p 53$ gene. ${ }^{22}$ Though the basal level of miR-34a was reduced in p53DD-expressing cells relative to the control cells expressing an empty vector, B-RAF induction in p53DD cells resulted in approximately ninefold upregulation of miR-34a relative to the level in normal p53DD cells (Figure 3c). The p53DD cells did not possess functional wild-type p53 activity, as p53 failed to induce p21 after treatment with 5-FU (Supplementary Figure S4b). Thus, we infer that miR-34a induction in this model system is dependent on mechanisms other than p53.

miR-34a expression is regulated by ELK1. The observation that regulation of miR-34a does not depend on p53 prompted us to look for alternative regulators of miR-34a expression during B-RAF-induced senescence. Phosphorylated ERK can activate a number of transcription factors, including ETS, AP-1, MYC and CREB. ${ }^{23}$ The primary miR-34a transcript is produced by the splicing of two exons located $30 \mathrm{~kb}$ apart, and the area downstream of the transcription start site is highly conserved between human, mouse and rat. ${ }^{16,17}$ Regulatory Vista (rVista) ${ }^{24}$ analysis of this region revealed the presence of multiple conserved transcription factor-binding sites, including a number of putative binding sites for members of the ETS family (Figure 4a). To test their functional significance, we depleted individual ETS family members from TIG3 TERT/ $\triangle B-R A F: E R$ cells using siRNA and measured miR-34a regulation after $B-R A F$ activation. Although knockdown of ETS1, ETS2 and ELF1 had little effect (Supplementary
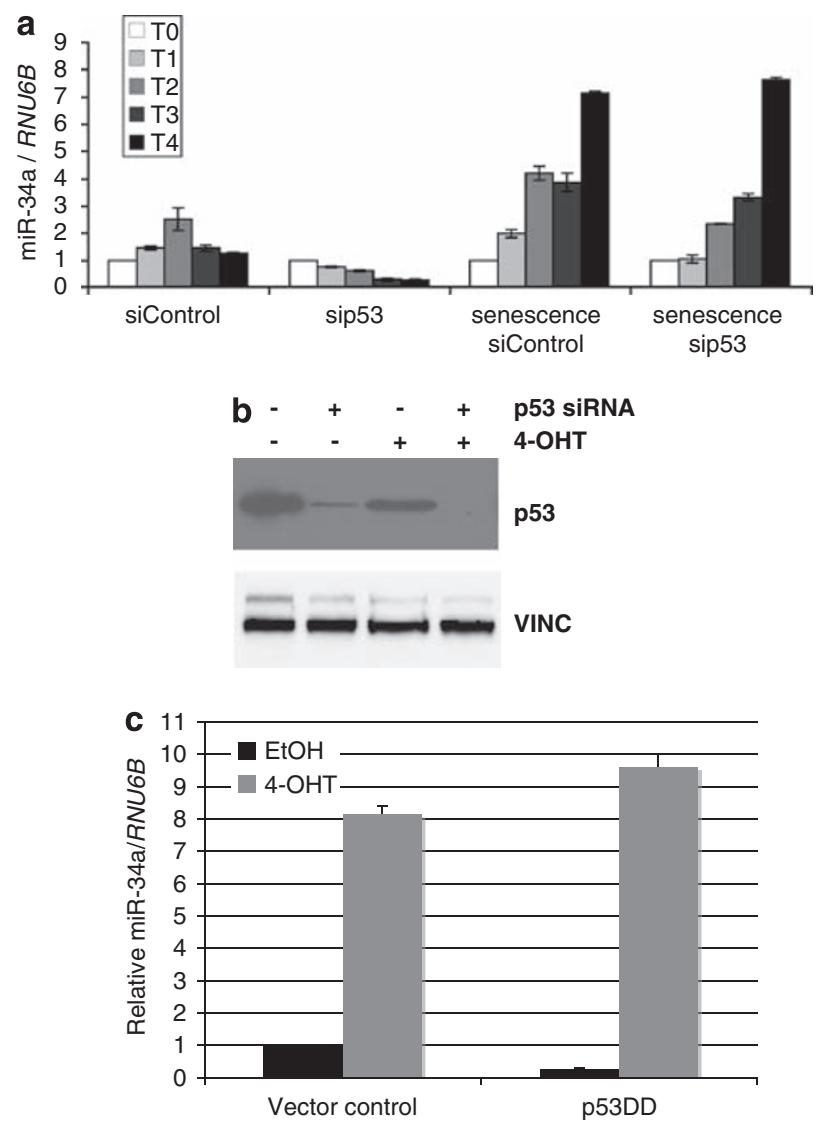

Figure 3 p53-independent increase of miR-34a expression during B-RAFinduced senescence. (a) miR-34a induction by B-RAF persists despite p53 knockdown. Transfection of TIG3 TERT/B-RAF:ER cells with $50 \mathrm{nM}$ siRNA followed by B-RAF induction by 4-OHT treatment. Values are normalised to RNU6B, related to T0 and shown as the mean \pm S.D. of three replicates. (b) Western blotting for p53 in TIG3 TERT/B-RAF:ER cells transfected with $50 \mathrm{nM}$ siRNA against p53 or a control siRNA, followed by 3 days of treatment with 4-OHT. (c) miR-34a induction by B-RAF is intact in TIG3 TERT/B-RAF:ER cells expressing a dominant-negative variant of $p 53$ (p53DD) on 3 days of treatment with 4-OHT

Figure S5), depletion of ELK1 significantly impaired B-RAF-mediated induction of miR-34a (Figure 4b) $(P<0.04$, Student's $t$-test). Efficient knockdown of ELK1 and ELF1 was confirmed at the MRNA and protein level (Supplementary Figure S6).

To verify the ability of ELK1 to regulate the human miR-34a promoter, we cloned a 760-bp fragment of the proximal promoter containing several putative ELK1-binding sites into a luciferase reporter vector (pProm34a). Co-transfections of pProm34a with an ELK1 expression construct into HEK293 cells resulted in a significant upregulation of luciferase activity $(P<0.002$, Student's $t$-test), showing the capacity of ELK1 to regulate the miR-34a promoter (Figure $4 \mathrm{c}$ ). To confirm the binding of ELK1 to the miR-34a promoter at the endogenous level, we carried out chromatin immunoprecipitation (ChIP) in TIG3 TERT/ $\triangle \mathrm{B}-\mathrm{RAF}$ :ER cells. We observed a strong enrichment of ELK1 on the miR-34a promoter after B-RAF activation (Figure 4d), consistent with the notion that ELK1 is an important regulator of miR-34a during oncogene-induced senescence in primary human fibroblasts. 

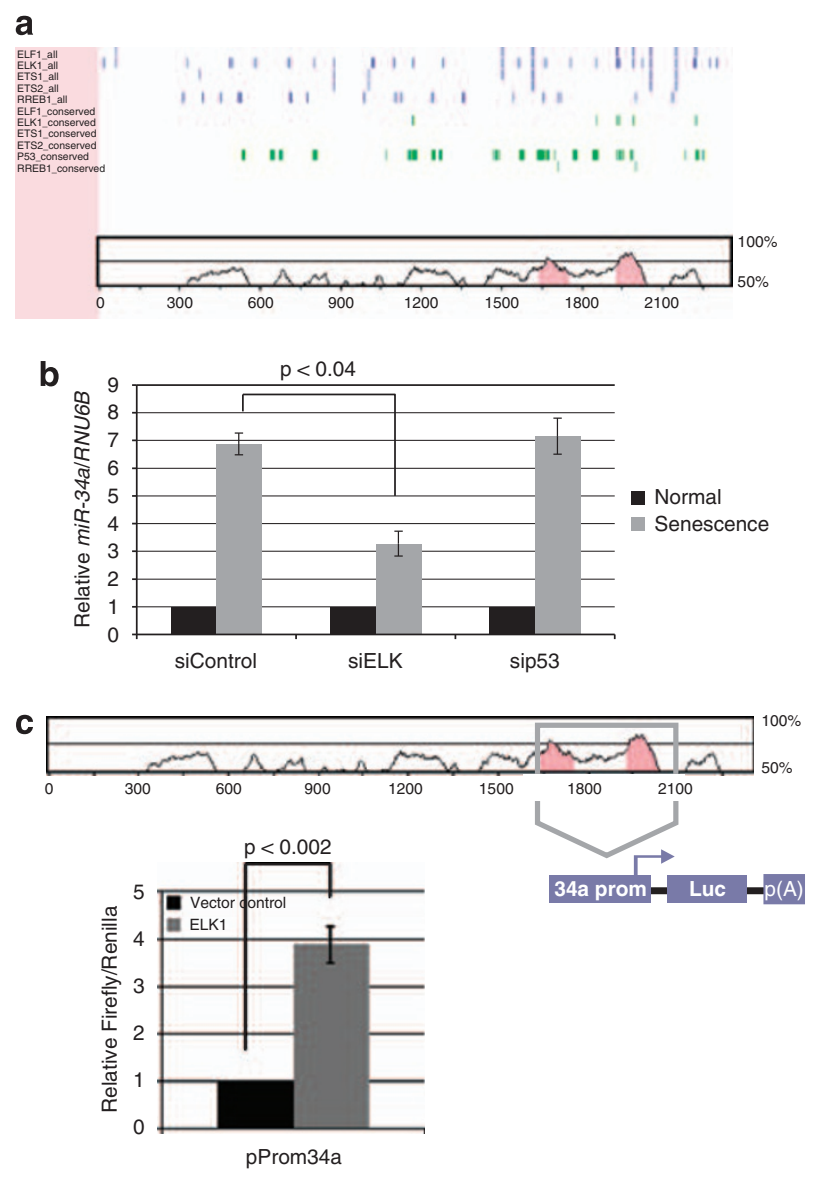

d
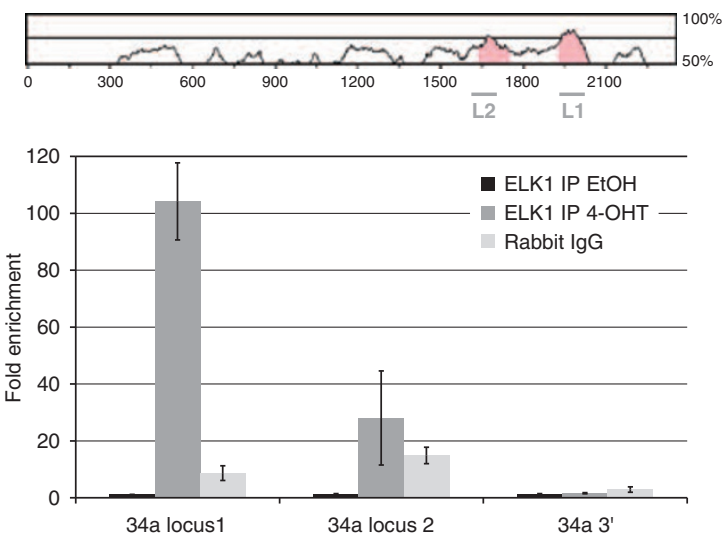

Figure 4 miR-34a expression is regulated by ELK1 in TIG3 TERT/B-RAF:ER cells undergoing senescence. (a) Vista sequence alignment of human and mouse miR-34a promoters with regulatory Vista analysis of transcription factor-binding motifs (Ensemb positions: hsa chr. 1:9.164.107-9.166.456 and mmu chr. 4:148.890.943148.894.943). Blue bars: motifs present in the human promoter; green bars: conserved motifs. (b) B-RAF-induced upregulation of miR-34a is attenuated by knockdown of ELK1. Values are normalised to RNU6B and shown relative to normal cells. Data are shown as the mean \pm S.E.M. of three independent experiments. (c) Exogenous ELK1 expression upregulates a luciferase reporter construct containing part of the human miR-34a promoter (pProm34a). Luciferase values (pProm34a) normalised to Renilla luciferase are shown relative to the empty vector control. (d) ELK1 binding to the miR-34a promoter increases on B-RAF activation. Chromatin immunoprecipitation of ELK1 with qPCR detection of two different loci (L1 and L2) within the miR-34a promoter as indicated in the upper panel. A downstream miR-34a locus is shown as negative control. Values are shown as the mean \pm S.D. of three replicates and are representative of three independent experiments
Identification of miR-34a targets in oncogene-induced senescence. To understand the role of miR-34a in oncogene-induced senescence, we tested global mRNA expression using microarrays of TIG3 TERT/DB-RAF:ER cells transfected with a miR-34a LNA inhibitor or a scrambled control LNA in the presence or absence of B-RAF activation. Affymetrix microarrays (Affymetrix, Santa Clara, CA, USA) were performed with total RNA from three biological replicates for each treatment. miR-34a and scrambled inhibitors were transfected into the cells at day 2 of $4-\mathrm{OHT}$ treatment (or $\mathrm{EtOH}$ as vector control) and the samples were harvested $24 \mathrm{~h}$ after transfection.

As expected, B-RAF activation resulted in major changes in gene expression, as evident from a hierarchical cluster analysis (Supplementary Figure S7 and Supplementary Table S3). Importantly, miR-34a inhibition resulted in de-repression of several transcripts that have previously been reported as miR-34a targets, including BCL2 and CDK6, and, to a lesser extent, MET and CCND1 (Supplementary Table S1).

To highlight changes related to miR-34a, we carried out hierarchical clustering analysis of the top $20 \%$ of the genes that were most influenced by miR-34a inhibition (Figure 5a). Although we did not detect an enrichment of motifs matching the miR-34a seed sequence within the $3^{\prime}$ UTRs of genes in clusters resulting from this data set $(\sim 1800$ transcripts), several clusters displayed an interesting miR-34a dependency. We focused on a cluster of $\sim 350$ transcripts, which were repressed upon B-RAF activation. Interestingly, the inhibition of miR-34a alleviated B-RAF-mediated repression of this cluster, which we have termed the 'B-RAF-repressed, miR-34a-influenced cluster' (Figure 5a). Functional annotation analysis ${ }^{25}$ of the cluster revealed a significant enrichment for genes related to the $M$ phase of the cell cycle $\left(P<5.7 \times 10^{-15}\right)$, the cell cycle $\left(P<1.9 \times 10^{-11}\right)$ and other related functions (Supplementary Table S2). Furthermore, CDK6 and BCL2, two well-known targets of miR-34a, ${ }^{13,26}$ were included in this cluster. As most of the transcripts in this cluster did not contain binding sites for miR-34a in their $3^{\prime}$ UTRs, we speculated that a common transcriptional regulator, which is a miR-34a target, could be responsible for the observed expression pattern and mediate a global miR-34a effect. Interestingly, when subjecting the promoters of the genes in the 'B-RAF-repressed, miR-34a-influenced cluster' to motif finding (using AMADEUS ${ }^{27}$ ), a marked enrichment for a motif resembling a MYC-binding site was found $\left(P<3.3 \times 10^{-12}\right)$, suggesting that miR-34a could influence gene expression through targeting of MYC.

miR-34a targets MYC during oncogene-induced senescence. Inspection of the $3^{\prime} \mathrm{UTR}$ sequence of $M Y C$ revealed the presence of a perfectly complementary and evolutionarily conserved 7-nucleotide match to the seed region of miR-34b and miR-34c, and a 6-nucleotide seed match to miR-34a (Supplementary Figure S8). miR-34b and miR-34c were recently reported to regulate MYC, ${ }^{26,27}$ but neither miR-34b nor miR-34c was detected above background in our miRNA microarray experiments on TIG3 TERT/AB-RAF:ER cells.

In the Affymetrix array data, we did not detect changes in the MYC mRNA level after miR-34a inhibition (Supplementary 


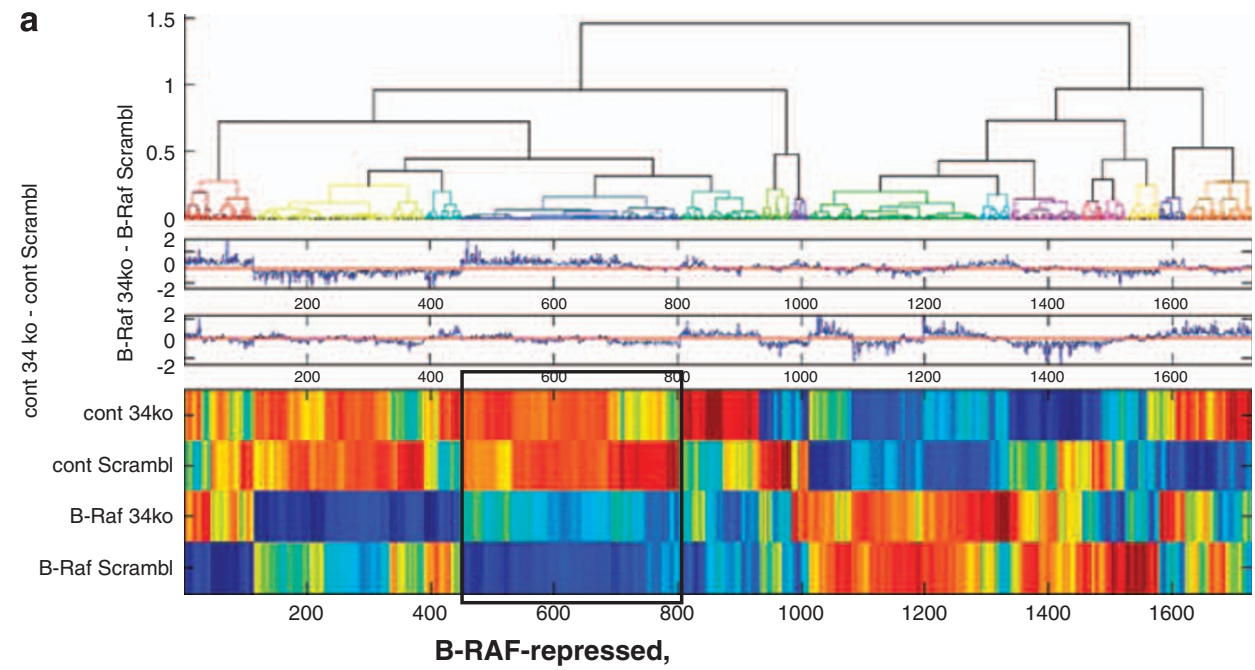

miR-34a-influenced cluster

b

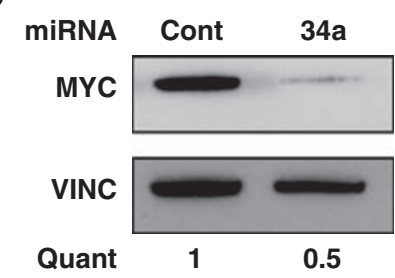

d

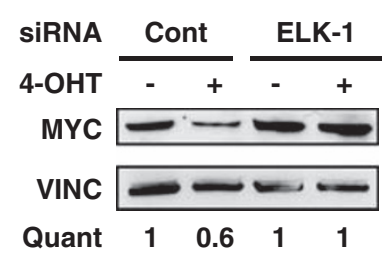

c

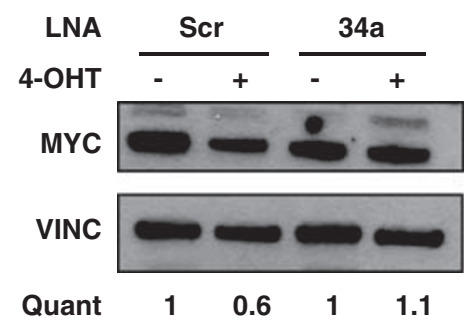

e

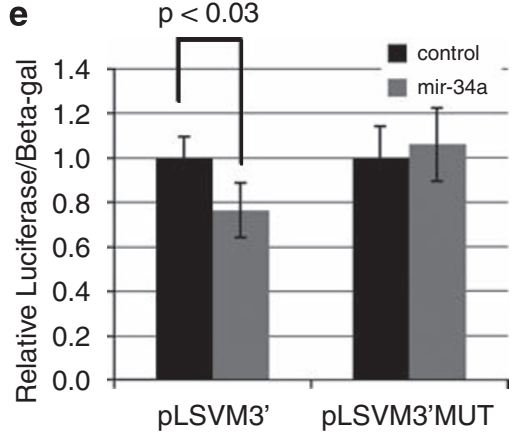

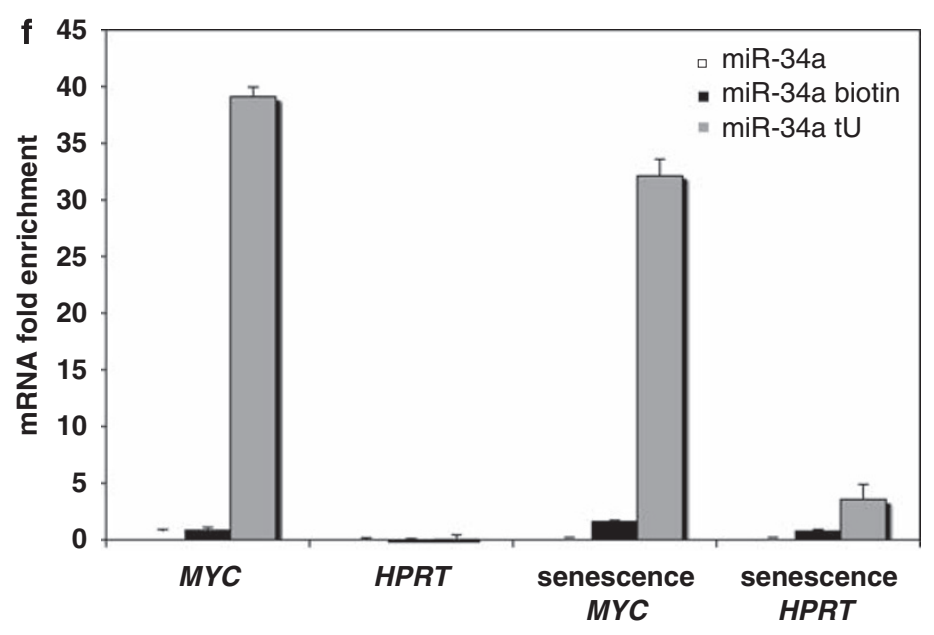


Figure S9a). Furthermore, overexpression of a miR-34a precursor in TIG3 TERT/AB-RAF:ER cells had little effect on $M Y C$ at the mRNA level (Supplementary Figure $\mathrm{S} 9 \mathrm{~b}$ ), suggesting post-transcriptional regulation at the level of translation. To investigate whether miR-34a can translationally regulate MYC, we transfected TIG3 TERT/DB-RAF:ER cells with a miR-34a precursor and controls and analysed the effect on MYC protein using western blotting (Figure $5 \mathrm{~b}$ ). Strikingly, miR-34a overexpression resulted in marked downregulation of endogenous MYC protein, indicating that miR$34 \mathrm{a}$ can affect cell proliferation through repression of MYC. Similar results were found in $\mathrm{H} 1299$ cells (Supplementary Figure S10). To test whether miR-34a represses MYC downstream of B-RAF activation, we induced B-RAF in TIG3 TERT/DB-RAF:ER cells and transfected the cells 2 days later with a miR-34a LNA inhibitor or scrambled LNA. As evident from Figure $5 c$, inhibition of miR-34a during senescence resulted in de-repression of MYC. This strongly suggests that miR-34a can affect a large cohort of cell cycle regulators through translational repression of $M Y C$. As we have shown that miR-34a is regulated by ELK1 downstream of B-RAF induction, we tested the ability of an siRNA against ELK1 to phenocopy the effect of miR-34a inhibition on MYC protein. As evident from Figure $5 \mathrm{~d}$, depletion of ELK1 did indeed cause de-repression of MYC protein during B-RAFinduced senescence, underlining the importance of ELK1 in miR-34a regulation during oncogene-induced senescence.

To test whether miR-34a regulates MYC in a direct manner, we measured the effect of the miR-34a precursor on a luciferase reporter construct containing the MYC $3^{\prime} U T R$ (pLSV-M3'). Although miR-34a significantly repressed luciferase activity of pLSV-M3' $(P<0,03$, Student's $t$-test), it did not affect a mutated version (pLSV-M3'MUT) in which the miR$34 \mathrm{a}$ seed-binding site had been altered (Figure $5 \mathrm{e}$ ). To further show the direct interaction between miR-34a and $M Y C$ mRNA, we carried out miRNA pull-out assays in which biotinylated miRNA mimics are transfected into cells, allowing for subsequent streptavidin-based purification of the mature miR-34a along with associated RNA species. ${ }^{28}$ The mature strand furthermore contained photosensitive 4-thiouridine
(4-tU) modified nucleotides, which form RNA-RNA crosslinks upon long-wave UV-irradiation. miR-34a hairpins were transfected into TIG3 TERT/ $\triangle \mathrm{B}-\mathrm{RAF}$ :ER cells in the presence and absence of B-RAF activation. The cells were UV treated to induce RNA cross-linking and after streptavidin pullout of biotinylated miR-34a, MYC mRNA was highly enriched in the RNA pool associated with miR-34a compared with a control mRNA, HPRT (Figure 5f). Thus, our data show that miR-34a regulates $M Y C$ through direct binding to its $3^{\prime} U T R$.

\section{Discussion}

Oncogene-induced senescence is an important barrier towards cancer in vivo, but the underlying mechanisms are still not clear and likely differ between cell types. miRNAs regulate numerous cellular processes and a current challenge is to understand their functions and incorporate individual miRNAs into cellular pathways. Here, we provide evidence that miR-34a is transcriptionally upregulated by ELK1 downstream of B-RAF oncogene activation, which leads to senescence in human fibroblasts. This is a novel pathway that is independent of p53, which was previously reported to transcriptionally activate miR-34a. In addition, we identify MYC as a miR-34a target. In agreement with the proliferative role of MYC, we show that MYC is repressed during oncogene-induced senescence and our data suggest that this repression is mediated, at least in part, through miR-34a. The effect of miR-34a extends further to repress a set of mitotic genes that are transcriptional targets of MYC, providing a novel link between B-RAF oncogene activation and the mechanism of senescence.

ELK1 mediates upregulation of miR-34a during B-RAFinduced senescence independently of p53. It was previously reported that exogenous expression of miR-34a induces senescence-like changes in primary cells and cancer cell lines. ${ }^{17,21}$ Accordingly, we find that exogenous expression of a miR-34a precursor induces a partial G1 cell cycle arrest and a senescence-like cell morphology in TIG3 TERT cells. Thus, our finding that B-RAF activation induces

Figure 5 MYC is directly targeted by miR-34a during senescence. (a) Hierarchical clustering of the top $20 \%$ of transcripts most highly affected by miR-34a inhibition. Top panel: Hierarchical clustering tree. Colours on the tree mark different clusters. Middle panel: Gene fold change (log2 scale) induced by a miR-34a inhibitor in normal cells (cont/ 34ko-cont/scrambl) and in senescent cells (B-RAF/34ko - B-RAF/scrambl). Bottom panel: Normalised expression data. For visualisation purposes, data were gene normalised by subtracting the mean for each gene value and dividing it by the standard deviation. 'Cont 34ko': Cells treated with EtOH carrier and transfected with an LNA inhibitor of miR-34a, 'Cont Scrambled': Cells treated with EtOH carrier and transfected with a scrambled LNA control. 'B-RAF 34ko': Cells treated with 4-OHT and transfected with an LNA inhibitor of miR-34a. 'B-RAF Scrambled': Cells treated with 4-OHT and transfected with a scrambled control LNA. The 'B-RAF-repressed, miR-34a-influenced cluster' is indicated. (b) miR-34a overexpression represses MYC at the protein level. Western blot of MYC in TIG3 TERT/B-RAF:ER cells transfected with $50 \mathrm{nM}$ miR-34a or a control miRNA. (c) Inhibition of miR-34a prevents reduction of MYC protein during senescence. Western blot analysis of MYC in TIG3 TERT/B-RAF:ER cells $24 \mathrm{~h}$ after transfection with $50 \mathrm{nM}$ of a miR-34a inhibitor or a scrambled control LNA, in the presence or absence of B-RAF induction (3 days). Numbers indicate quantification of the MYC band densities relative to Vinculin. (d) Depletion of ELK1 by siRNA prevents reduction of MYC protein during senescence. Western blot analysis of MYC in TIG3 TERT/BRAF:ER cells $24 \mathrm{~h}$ after transfection with $50 \mathrm{nM}$ of siRNA against ELK1 or a control siRNA, followed by 3 days of B-RAF induction. Numbers indicate quantification of the MYC band densities relative to Vinculin. (e) miR-34a regulates MYC through binding to the MYC $3^{\prime}$ UTR. TIG3 TERT/B-RAF:ER cells were co-transfected with miR-34a or a control miRNA and a wild type or mutated version of the MYC $3^{\prime} U T R$ cloned into a luciferase vector (pLSVM3' and pLSVM3'MUT, respectively). Luciferase values were normalised to $\beta$-galactosidase activity and are shown relative to control as the mean + I-S.D. of three replicates. The data are representative of three independent experiments. (f) miRNA pull-out assay demonstrating direct binding of miR-34a to the $3^{\prime}$ UTR of MYC mRNA in normal and senescent TIG3 TERT/B-RAF:ER cells. After 2 days of treatment with 4-OHT or EtOH carrier, TIG3 TERT/B-RAF:ER cells were transfected with $30 \mathrm{nM}$ of an unmodified miR-34a duplex (miR-34a), a biotinylated miR-34a duplex (miR-34a Biotin) or a mix of two biotinylated miR-34a duplexes containing UV-reactive 4-thiouridine (4-tU) nucleotides at positions 7 and 11, respectively (miR-34a tU). The transfected cells were UV irradiated to induce cross-linking of the 4-tU nucleotides to associated mRNAs. On extraction of biotinylated duplexes, the presence of MYC mRNA or a control (HPRT) mRNA was measured by qPCR 
an upregulation of miR-34a in TIG3 cells suggests that miR-34a is a mediator of B-RAF-induced senescence. Dysregulation of miR-34a has been reported for several types of cancer, suggesting its importance as a tumour suppressor. miR-34a expression is downregulated in neuroblastomas $^{29}$ and frequently reduced in pancreatic cancers cell lines. ${ }^{14}$ Furthermore, miR-34a resides in a locus (1p36), which is frequently lost in cancer ${ }^{30}$ and is subject to silencing because of aberrant CpG methylation of the promoter in prostate cancer and melanoma, as well as a number of cancer cell lines. ${ }^{31}$

Transcriptional regulation of miR-34a has so far been ascribed to p53 and there is substantial evidence that p53 transcriptionally activates miR-34a after DNA damage, whereas the absence of p53 activity abrogates miR-34a regulation. ${ }^{16,17}$ In contrast, we find that depletion of functional p53 by siRNA or by overexpression of dominant-negative p53DD does not markedly affect the induction of miR-34a in normal versus oncogene-induced senescent cells, and thus we speculate that B-RAF oncogenic stress induces miR-34a expression through different pathways than those induced by DNA damage. In support of p53-independent regulation of miR-34a downstream of B-RAF activation, it has previously been shown in human IMR-90 fibroblasts that $\triangle R A F-1$ :ER induces irreversible cellular senescence through activation of the MAP-kinase pathway independently of p53 and p21. ${ }^{20}$ Although $p 53$ is not necessary for miR-34a regulation in senescent TIG3 cells, p53 depletion does decrease the basal level of miR-34a in normal TIG3 cells, indicating that p53 may regulate miR-34a in this cell type under different conditions.

To identify novel regulators of miR-34a downstream of $\mathrm{B}-\mathrm{RAF}$, we analysed the promoter region of the human miR-34a gene for relevant transcription factor-binding sites. Among other transcription factors, B-RAF activates members of the ETS family, which has previously been implicated in cellular senescence because of the ability of ETS1 and ETS2 to activate the p16INK4a promoter. ${ }^{32}$ The human miR-34a promoter region contains several ETS-binding motifs, including that of ETS1, ETS2, ELF1 and ELK1. It can be noted that several conserved ELK1 motifs occur in a part of the miR-34a promoter region that is highly conserved between mouse and human. Knockdown of ELK1, but not ETS1, ETS2 and ELF1, reduces the induction of $\mathrm{miR}-34 \mathrm{a}$ in senescent cells after B-RAF activation. Furthermore, an ELK1 expression construct markedly increases activity of a reporter construct containing part of the human miR-34a promoter. Finally, we show increased recruitment of ELK1 to the miR-34a promoter in TIG3 cells 3 days after B-RAF activation relative to control TIG3 cells. Collectively, these data show that ELK1 can activate the miR-34a promoter after B-RAF activation in a p53-independent manner.

miR-34a targets the MYC proto-oncogene during B-RAF-induced senescence. The data presented by us and others suggest a functional importance of miR-34a in senescence. ${ }^{17,21,33}$ To identify miR-34a target genes involved in senescence, we used Affymetrix microarray analysis to measure gene expression in normal and senescent TIG3 cells treated with a miR-34a-specific inhibitor. We and others have previously used this strategy to identify targets for miR-21..$^{34,35}$ Using this approach, transcripts that are de-repressed by miR-34a in the level of mRNA degradation can be identified by their increased abundance, whereas mRNAs regulated exclusively at the level of translation cannot be directly detected. Importantly, as evident from this study, detailed analysis of the promoters of cohorts of deregulated genes can lead to the identification of translationally regulated targets. Although B-RAF activation has a major impact on gene expression, we were able to detect genes, the expression of which was alleviated by miR-34a inhibition, as visualised by hierarchical clustering of the $20 \%$ genes that are most highly regulated by the miR-34a inhibitor in normal and/or senescent TIG3 cells. We do not observe an overrepresentation of the miR-34a-binding site in this list of genes. However, consistent with previous reports, we find that miR-34a inhibition de-represses four validated miR-34a targets, namely, BCL2, CDK6, CCND1 and $M E T,^{13,16,17,36}$ although de-repression of $C C N D 1$ and MET were modest at the mRNA level and did not belong to the top $20 \%$ genes most highly regulated by miR-34a inhibition. We therefore suspected translational inhibition to be a major component of miR-34a function, which prompted us to search for secondary regulatory effects present in the data, and to identify the primary regulator upstream to these.

Cluster analysis of the top $20 \%$ of genes affected by miR34 a depletion revealed a set of genes (the 'B-RAF-repressed, miR-34a-influenced cluster'), which is functionally enriched for mitotic genes and for genes harbouring putative MYCbinding sites in their promoters. We find that a miR-34a precursor represses MYC protein in TIG3 cells and other cell types, and importantly, we show that miR-34a inhibition derepresses MYC protein levels in cells undergoing B-RAFinduced senescence. Interestingly, we find that ELK1 depletion phenocopies the effect of miR-34a inhibition on MYC, thereby supporting the notion that ELK1 upregulates miR-34a during B-RAF-induced senescence and that miR-34a in turn represses MYC. Our data furthermore show direct interaction between miR-34a and the MYC $3^{\prime} U T R$, in that miR-34a can repress the activity of a wild type but not a mutated $M Y C$ $3^{\prime}$ UTR reporter and $M Y C$ mRNA is highly enriched in the RNA pool associated with miR-34a in a miRNA pull-out assay.

Members of the miR-34 family have previously been linked to the MYC family of proto-oncogenes. In neuroblastoma, loss of the 1p36 locus, which encodes miR-34a as well as other potential tumour suppressors, correlates with NMYC amplification and miR-34a targets NMYC in several human neuroblastoma cell lines. ${ }^{37}$ In addition, miR-34b and mir-34c were recently reported to target $\mathrm{MYC}^{38,39}$ The binding site for miR-34a in the $3^{\prime} U T R s$ of $M Y C$ is furthermore conserved in the genomes of humans, mice, rats, dogs and chicken. When taken together with the published data, our data thus suggest an evolutionarily conserved regulation of several members of the MYC family of proto-oncogenes by miR-34 family members.

Several lines of evidence implicate MYC in oncogeneinduced senescence, and show that its repression is essential for the senescent phenotype. A recent report showed that MYC depletion in B-RAF or N-RAS overexpressing melanoma cells results in senescence-like phenotypes and that MYC overexpression repressed B-RAF-induced senescence. ${ }^{40}$ 
Likewise, inactivation of MYC in primary tumours induced by conditional MYC overexpression induces senescence and tumour regression, ${ }^{41}$ and reduced MYC levels in normal diploid human fibroblasts increases the frequency of telomere-independent senescence in a p16-dependent manner. ${ }^{42}$ In view of this, we propose that miR-34a functions downstream of B-RAF to downregulate MYC protein levels in TIG3 TERT/AB-RAF:ER cells, thereby promoting B-RAFinduced senescence. However, in this cellular system, inhibition of miR-34a alone did not prevent the appearance of phenotypic hallmarks of senescence, such as senescenceassociated heterochromatic foci and increased SA- $\beta$-gal activity (data not shown). Hence, miR-34a is an important but not a sole player in B-RAF-induced senescence in these cells, and other mediators have yet to be identified.

In summary, we have shown that human primary cells undergoing B-RAF-induced senescence strongly upregulate miR-34a in a p53-independent manner. Instead, the regulation is mediated, at least partly, by the ETS family transcription factor, ELK1. In addition, during senescence miR-34a affects the expression of a cluster of mitotic genes through translational repression of MYC. This places miR-34a at a key node, responding to several independent cancer-associated pathways, and emphasises the importance of miR-34a as a tumour suppressor.

\section{Materials and Methods}

Cell culture. TIG3 TERT/B-RAF:ER cells are primary human diploid fibroblasts immortalised by hTERT. B-RAF is constitutively active because of truncation of the regulatory N-terminal domain and is fused to the hormone-binding domain of the oestrogen receptor, which was modified to respond to $4-\mathrm{OHT}$ but not $\beta$-estradiol. ${ }^{43}$ TIG3 and HEK293 cells were maintained in Dulbecco's modified Eagle's medium (DMEM) with 10\% FBS (Biochrom AG, Berlin, Germany), $100 \mathrm{U} / \mathrm{ml}$ penicillin and $100 \mu \mathrm{g} / \mathrm{ml}$ streptomycin (Invitrogen, Carlsbad, CA, USA) and incubated at $37^{\circ} \mathrm{C}$ in $5 \% \mathrm{CO}_{2}$. For conditional activation of B-RAF, TIG3 TERT/B-RAF:ER cells were treated for 3 days with $500 \mathrm{nM} 4-\mathrm{OHT}$ or equal volumes of EtOH carrier. For 5-FU treatment, cells were incubated for $16 \mathrm{~h}$ with $50 \mu \mathrm{g} / \mathrm{ml} 5$-FU or equal volumes of DMSO carrier.

TIG3 TERT/B-RAF:ER p53DD cells were produced by infection of TIG3 TERT/BRAF:ER with p53DD virus followed by puromycin selection.

miRNA precursors, anti-miRNA oligonucleotides and siRNA. The miRNA precursors were purchased from Ambion (Austin, TX, USA) and LNA-modified oligonucleotide miRNA inhibitors from Exiqon (Vedbaek, Denmark). SMARTpool siRNAs were purchased from Dharmacon (Lafayette, CO, USA), except the siRNA against $p 53$, which was an annealed duplex of the following oligonucleotides purchased from Biosynthesis (Lewiseville, TX, USA):

hsa p53i $S 5^{\prime}$-CTACATGTGTAACAGTTCCUU- ${ }^{\prime}$ and

hsa p53i AS 5'-(P)-GGAACTGTTACACATGTAGUU- $3^{\prime}$

The AllStars-negative control siRNA (Qiagen, Valencia, CA, USA) was used as control for transfections with miRNA precursors and siRNAs.

Vector constructs. pProm34a: A 760-bp fragment of the human miR-34a promoter was PCR amplified from human genomic DNA and cloned into the pGL3 Basic vector (Invitrogen) using $\mathrm{Xhol}$ and Hindlll restriction enzymes. The primer sequences were (restriction sites are underlined):

FW 5'-CTCGAGCGAGCAGGAAGGAGGACCCG-3' and

\section{RV 5'-AAGCCTGGGCTCCAGCCAGCAGGG- $3^{\prime}$.}

The ELK1 expression construct was kindly provided by Dr. Robert A Hipskind. The MYC luciferase constructs pLSV-M3' and PLSV-M3'MUT were kindly provided by Dr. Martin Bushell.

Reporter assays. For promoter luciferase assays, HEK293 cells were seeded at 10000 per 96 well and transfected (Lipofectamine 2000, Invitrogen) on the next day with $150 \mathrm{ng}$ pProm34a, $25 \mathrm{ng} \mathrm{pRL}-\mathrm{TK}$, and $100 \mathrm{ng}$ of an ELK1 expression vector or an empty pcDNA3.1 + vector. At $48 \mathrm{~h}$ after transfection, luciferase activity was measured using the Dual-Glo luciferase assay (Promega, Stockholm, Sweden).

For MYC 3'UTR luciferase assays, 80000 TIG3 TERT/B-RAF:ER cells per 24 well were reverse transfected (Lipofectamine 2000) with $1.75 \mu \mathrm{g} \mathrm{pLSV}-\mathrm{M}^{\prime}$ or pLSV-M3'MUT, $50 \mathrm{nM}$ miR-34a or AllStars control, and $0.25 \mu \mathrm{g}$ lacZ expression vector (pCMV-b-gal, Clontech, Palo Alto, CA, USA). At $20 \mathrm{~h}$ after transfection, cells were washed once in PBS, lysed in $100 \mu$ l Passive Lysis Buffer (Promega) and incubated for $20 \mathrm{~min}$ at RT. In all, $10 \mu$ l of lysate was mixed with $90 \mu$ l of complete luciferase buffer $\left(25 \mathrm{mM}\right.$ glycylglycine, $15 \mathrm{mM} \mathrm{MgSO}_{4}, 4 \mathrm{mM}$ EGTA, $100 \mathrm{mM}$ $\mathrm{KH}_{2} \mathrm{PO}_{4}$ buffer, $1 \mathrm{M}$ DTT, $0.2 \mathrm{M}$ ATP (Sigma) and $10 \mu \mathrm{M}$ Luciferin (Sigma)) and Luciferase activity was measured immediately. $\beta$-galactosidase activity was measured by mixing $25 \mu \mathrm{l}$ lysate, $175 \mu \mathrm{l}$ Z-buffer $\left(100 \mathrm{mM} \mathrm{Na}_{2} \mathrm{PO}_{4} \mathrm{pH} 7,10 \mathrm{mM}\right.$ $\mathrm{KCl}, 1 \mathrm{mM} \mathrm{Mg}_{2} \mathrm{SO}_{4}$ and $5 \mathrm{mM} \mathrm{DTT}$ ) and $40 \mu$ ortho-nitrophenyl- $\beta$-galactoside (ONPG) reaction mix ( $4 \mathrm{mg} / \mathrm{ml}$ ONPG, $100 \mathrm{mM} \mathrm{Na}_{2} \mathrm{PO}_{4} \mathrm{pH}$ 7), and incubating at $37^{\circ} \mathrm{C}$. Production of ortho-nitrophenol was measured at $410 \mathrm{~nm}$.

qPCR analysis. For qPCR of mRNA, TIG3 TERT/B-RAF:ER cells were seeded at 250000 per six well, transfected twice on two successive days with $50 \mathrm{nM}$ siRNA using Lipofectamine 2000 (Invitrogen) according to the manufacturer's protocol, and treated with $500 \mathrm{nM} 4-\mathrm{OHT}$ or equal volumes of ethanol the next day. Total RNA was prepared using TRIzol reagent (Invitrogen), treated with DNase and reverse transcribed using TaqMan Reverse Transcription kit (Applied Biosystems, CA, USA) with random hexamer primers. qPCR detection of human p53, ELF1, ELK1, MYC and GAPDH was performed with TaqMan gene expression assays (Applied Biosystems) according to the manufacturer's protocol. For miRNA qPCR, total RNA was prepared using TRlzol reagent. Reverse transcription and qPCR analyses were carried out with TaqMan miRNA assays (Applied Biosystems) for hsamiR-34a, hsa-miR-146a and RNU6B.

Antibodies and western blot analysis. TIG3 TERT/B-RAF:ER cells were seeded at 250000 per six well, transfected with $50 \mathrm{nM}$ miRNA precursor using Lipofectamine 2000 and treated with $500 \mathrm{nM} 4-\mathrm{OHT}$ or equal volumes of ethanol the next day. Cells were harvested, washed once in PBS and lysed in RIPA buffer $(150 \mathrm{nM} \mathrm{NaCl}, 0.5 \%$ sodium deoxycholate, $0.1 \%$ SDS, $50 \mathrm{mM}$ Tris- $\mathrm{HCl} \mathrm{pH} 8,2 \mathrm{mM}$ EDTA) containing $1 \mathrm{mM}$ DTT and $1 \mathrm{mM}$ Pefabloc (Roche, Indianapolis, IN, USA). In all, $20 \mu \mathrm{g}$ protein/lane was separated on a 4-20\% NuPAGE Bis-Tris gel (Invitrogen) and transferred to a nitrocellulose membrane. The antibodies used were as follows - ELF1: sc-631, Santa Cruz Biotechnology (Santa Cruz, CA, USA); ELK1: \#9182, Cell Signaling (Denvers, MA, USA); MYC: \#9402, Cell Signaling; p16: monoclonal Ab DCS50; p53: sc-126, Santa Cruz Biotechnology; Vinculin: V9131, Sigma. The antibodies for ChIP were ELK1: sc-355X, Santa Cruz Biotechnology; Rabbit IgG (Sigma I 8140).

Cell cycle analysis. To analyse the effect of miR-34a overexpression on the cell cycle, TIG3 TERT/B-RAF:ER cells were transfected with $50 \mathrm{nM}$ of miR-34a or AllStars control, stained for DNA content using propidium iodide and analysed on a FACSCalibur flow cytometer (Becton-Dickinson, Franklin Lakes, NJ, USA). Briefly, the cells were harvested by trypsinisation and washed once in PBS before fixing o/n in $70 \% \mathrm{EtOH}$. To stain the DNA, the cells were pelleted, resuspended in $100 \mu \mathrm{l}$ $\mathrm{EtOH}$ and stained for $1 \mathrm{~h}$ with $300 \mu \mathrm{l} \mathrm{PI}$ staining solution $(0.05 \mathrm{mg} / \mathrm{ml}$ propidium iodide, $20 \mu \mathrm{g} / \mathrm{ml}$ RNase A in $0.1 \% \mathrm{BSA}$ ).

ChIP. TIG3 TERT/B-RAF:ER cells were treated with $500 \mathrm{nM} \mathrm{4-OHT}$ or equal volumes of ethanol the day after seeding at $2.5 \times 10^{6}$ per $15-\mathrm{cm}$ plate and cultured for 3 days. To induce protein-protein cross-links, cells were first fixed for $30 \mathrm{~min}$ on ice with $5 \mathrm{mM}$ dimethyl $3^{\prime}$-dithiobispropionimidate (DTBP, Pierce Biotechnology, Rockford, IL, USA) in cold PBS (pH 8). ${ }^{44}$ After two washes in cold PBS (pH 8), remaining DTBP activity was stopped by incubation in DTBP quenching buffer ( $100 \mathrm{mM}$ Tris- $\mathrm{HCl}, \mathrm{pH} 8,150 \mathrm{mM} \mathrm{NaCl}$ ) for $10 \mathrm{~min}$ on ice. Next, cells were fixed by addition of $1 \%$ formaldehyde in cell culture medium and 10-min incubation at RT. Fixation was stopped by addition of $0.125 \mathrm{M}$ glycine and 5-min incubation at RT. After washing twice in PBS, cells from four to six plates were harvested with a cell scraper in $10 \mathrm{ml}$ SDS buffer $(0.1 \mathrm{M} \mathrm{NaCl}, 50 \mathrm{mM}$ Tris-HCl pH $8,5 \mathrm{mM}$ EDTA pH 8 , $0.2 \% \mathrm{NaN}_{3}, 0.5 \%$ SDS) containing Pefabloc and $1 \times$ Complete Mini protease inhibitor cocktail (Roche). Cells were pelleted at 1200 r.p.m. and resuspended in $2 \mathrm{ml} \mathrm{IP}$ buffer (1 volume SDS buffer:0.5 volume Triton dilution buffer $(0.1 \mathrm{M}$ Tris- $\mathrm{HCl}$ $\mathrm{pH}$ 8.6, $0.1 \mathrm{M} \mathrm{NaCl}, 5 \mathrm{mM}$ EDTA pH 8, $0.2 \% \mathrm{NaN}_{3}, 5 \%$ Triton-X-100)). Cells were 
sonicated for $6 \times 30$ s with a Branson Sonifier (Sonifier, Danbury, CT, USA) to obtain DNA fragments of 500-1000 bp. The lysates were precleared for $2 \mathrm{~h}$ with 4 Fast Flow protein A beads (GE Healthcare, Princeton, NJ, USA) that were blocked $\mathrm{o} / \mathrm{n}(0.2 \mathrm{mg} / \mathrm{ml}$ salmon sperm DNA, $0.5 \mathrm{mg} / \mathrm{ml}$ lipid-free $B S A)$ and washed in IP buffer. After removal of beads, lysates were diluted in IP buffer corresponding to $\sim 5 \times 10^{6} \mathrm{cells} / \mathrm{ml}$ and $1-\mathrm{ml}$ aliquots were incubated rotating o/n at $4^{\circ} \mathrm{C}$ with primary antibody against ELK1 (Santa Cruz sc-355 X) or rabbit lgG (Sigma I 8140). In addition, $10 \mu \mathrm{l}$ aliquots were saved as total control samples (1\%). Immune complexes were recovered by incubation with blocked protein $A$ beads for $4 \mathrm{~h}$ at $4^{\circ} \mathrm{C}$ and precipitated at $1800 \times \mathrm{g}$ at $4^{\circ} \mathrm{C}$. Beads were then washed in cold buffers as follows: thrice in $1 \mathrm{ml}$ mixed micelle wash buffer $(150 \mathrm{mM} \mathrm{NaCl}, 10 \mathrm{mM}$ Tris- $\mathrm{HCl} \mathrm{pH}$ $8,5 \mathrm{mM}$ EDTA pH 8, $5 \%$ w/v sucrose, $0.02 \% \mathrm{NaN}_{3}, 1 \%$ Triton-X-100, $0.2 \%$ SDS), twice in $1 \mathrm{ml}$ buffer 500 ( $50 \mathrm{mM}$ HEPES, pH 7.5, $1 \mathrm{mM}$ EDTA, $500 \mathrm{mM} \mathrm{NaCl}, 0.2 \%$ $\mathrm{NaN}_{3}, 1 \%(\mathrm{v} / \mathrm{v})$ Triton X-100, 0.1\% (w/v) deoxycholic acid), twice in $1 \mathrm{ml} \mathrm{LiCl} /$ detergent solution (10 mM Tris-HCl pH 8, $1 \mathrm{mM}$ EDTA, $250 \mathrm{mM} \mathrm{LiCl,} \mathrm{0.5 \%} \mathrm{(w/v)}$ deoxycholic acid (sodium salt), $0.5 \%$ (v/v) IGEPAL, $0.2 \% \mathrm{NaN}_{3}$ ) and once in $1 \mathrm{mI} \mathrm{TE}$ buffer. Samples were inverted 10 times during each wash. Immune complexes were eluted from beads by o/n shaking incubation at $65^{\circ} \mathrm{C}$ in $1 \% \mathrm{SDS}, 0.1 \mathrm{M} \mathrm{NaHCO}_{3}$ (both IP and input samples) and protein was removed by proteinase $\mathrm{K}$ treatment of the supernatant. DNA was extracted with 1 volume phenol:chloroform:isoamylic alcohol $(25: 24: 1)$ and ethanol precipitated. qPCR was carried out with SybrGreen qPCR master mix (Applied Biosystems) using the following primers:

miR-34a locus 1 (L1): 34a ChIP F1 5'-TGGCACGAGCAGGAAGGAGG-3' and 34a ChIP R1 5'-GCAGGACTCCCGCAAAATCTCC-3'.

miR-34a locus 2 (L2): 34a ChIP F2 5'-AATTGTGTAGCCTCCGTAAGGGGA-3' and

34a ChIP R2 5'-GAAAGAACTAGCCGAGCAAAACCC-3'.

miR-34a $3^{\prime}$ locus: 34a ChIP $3^{\prime}$ F $5^{\prime}$-GGACTTCGGAAGCTCTTCTGCG-3' and 34a ChIP $3^{\prime} R 5^{\prime}$-CACCAAGCCCCTGTGCCTTTT-3'.

miRNA pull-out assay. TIG3 TERT/B-RAF:ER cells were treated for $48 \mathrm{~h}$ with $500 \mathrm{nM} 4-\mathrm{OHT}$ or equal volumes of EtOH carrier. Cells were then transfected with $30 \mathrm{nM}$ miR-34a duplex, $3^{\prime}$ biotin-tagged miR-34a duplex or a mix of two $3^{\prime}$ biotin-tagged miR-34a duplexes containing a UV-reactive 4-tU nucleotide at positions 7 and 11, respectively. At $24 \mathrm{~h}$ after transfection, the cells were irradiated with long UV light $(365 \mathrm{~nm})$ for 5 min to induce cross-linking of 4-tU nucleotides to RNA, and immediately after this, total RNA was extracted by TRIzol (Invitrogen). After DNase treatment, $10 \mu \mathrm{g}$ RNA was incubated for $2 \mathrm{~h}$ with streptavidinconjugated beads (GE Healthcare) and washed with DEPC water. RNA was then purified by TRIzol and analysed using GPCR. To measure enrichment of MYC transcript, a standard curve was prepared, and HPRT enrichment was used as a negative control. For quantification, $500 \mathrm{ng}$ RNA was reverse transcribed using TaqMan Reverse Transcription Reagents (Applied Biosystems) according to the manufacturer's instructions. qPCR was carried out using SybrGreen PCR mastermix (Applied Biosystems) and the following primers:

HPRT FW: $5^{\prime}$-AGCCAGACTTTGTTGGATTTG-3'

HPRT REV: $5^{\prime}$-TTTACTGGCGATGTCAATAAG-3'

MYC FW: 5'-CCTCGGATTCTCTGCTCTC-3'

MYC REV: $5^{\prime}$-TTCTTGTTCCTCCTCAGAGTC-3'.

Microarray analyses. For miRNA microarrays, TIG3 TERT/B-RAF:ER cells were treated with $500 \mathrm{nM} \mathrm{4-OHT}$ or equal volumes of ethanol on the day after seeding at $1 \times 10^{6}$ per $10-\mathrm{cm}$ plate, in four biological replicates. Total RNA was harvested $72 \mathrm{~h}$ later using TRIzol reagent. miRNA microarray analysis (NCode Multi-Species miRNA Microarray V2, Invitrogen) was carried out at the Microarray Center, Rigshospitalet, Copenhagen University Hospital. Briefly, small RNAs $(<200$ nucleotides) were isolated from total RNA with the PureLink miRNA Isolation kit (Invitrogen). Purified small RNA concentration was measured with a NanoDrop 1000 spectrophotometer (Thermo Scientific, Waltham, MA, USA), and $1200 \mathrm{ng}$ of purified small RNA was labelled using the NCode miRNA Labelling System (Invitrogen). Briefly, small RNAs were poly(A)-tailed and ligated to a capture sequence. The tagged and tailed miRNAs were subsequently hybridised to the array following the manufactures instructions. Bound miRNAs were detected by another round of hybridisation of branched DNA structures containing Alexa Fluor 3 or Alexa Fluor 5 dye molecules (Invitrogen). All hybridisations were carried out in a MAUI Hybridization System (BioMicro Systems, Salt Lake City, UT, USA). The arrays were scanned in Agilent DNA Microarray Scanner (Agilent Technologies,
Santa Clara, CA, USA) and image files were analysed with Genepixe Pro 6.0 software (Molecular Devices, Sunnyvale, CA, USA) (E-MEXP-2038).

For Affymetrix microarrays, TIG3 TERT/B-RAF:ER cells were treated with $500 \mathrm{nM} 4-\mathrm{OHT}$ or equal volumes of ethanol on the day after seeding at $1 \mathrm{E} 6$ per $10-\mathrm{cm}$ plate, in three biological replicates. After 2 days of $4-\mathrm{OHT}$ treatment, cells were transfected with LNA-miR-34a or a control LNA-scramble using Lipofectamine 2000 (Invitrogen). Total RNA was harvested $24 \mathrm{~h}$ after transfection (3 days of 4-OHT treatment in total) using TRIzol reagent. Affymetrix microarray analysis (HG-U133 Plus 2.0 human) was carried out at the Microarray Center, Rigshospitalet, Copenhagen University Hospital. Briefly, double-stranded cDNA was synthesised from $2 \mu \mathrm{g}$ total RNA using Superscript Choice System (Invitrogen) with an oligo-(dT) primer containing a T7 RNA polymerase promoter. Biotin-labelled antisense cRNA was subsequently in vitro transcribed from CDNA (BioArray High Yield RNA Transcript Labelling kit; Enzo Diagnostics, Farmingdale, NY, USA). After fragmentation at $94^{\circ} \mathrm{C}$ for $35 \mathrm{~min}$ ( $40 \mathrm{mM}$ Tris, $30 \mathrm{mM} \mathrm{MgOAc}, 10 \mathrm{mM} \mathrm{KOAc}$ ), samples were hybridised to arrays for $16 \mathrm{~h}$. Upon washing and staining with phycoerytrin-conjugated streptavidin, the arrays were scanned in an Affymetrix GeneArray 2500 scanner as described in the Affymetrix GeneChip protocol. Data have been deposited at ArrayExpress (E-MEXP-2241).

Bioinformatics analyses. The data from miRNA microarrays were analysed with the BRB-ArrayTools V3.7.0 developed by Dr. Richard Simon and BRBArrayTools Development Team (http://inus.nci.nih.gov/BRB-ArrayTools.html). Triplicate probe sets were averaged and global normalisation was used to derive the median of the centre of the log-ratios on each array to adjust for the differences in labelling intensities of the Alexa Fluor 3 and Alexa Fluor 5 dyes. We identified miRNAs that were differentially expressed among the two classes using a random-variance $t$-test. Genes were considered statistically significant if their $P$-value was $\leqslant 0.001$.

The data from the Affymetrix array analyses were filtered to contain only probe sets present in at least one sample, in at least two out of three biological replicates. Replicate probe set intensities were averaged and the data were log2 transformed. Probe set annotation from Affymetrix (HG-U133_Plus_2.na25.annot.csv) was mapped to RefSeq IDs. Probe sets with ambiguous mapping (matching more that a single NM) were discarded and probe sets representing the same NM were averaged, resulting in 10184 RefSeq genes. For clustering analysis, we computed the effect of miR-34a inhibition in regular and senescent TIG3 cells, and selected the top $5 \%$ most upregulated and $5 \%$ most downregulated genes in each pair of samples (the 4-OHT/LNA-miR-34 versus 4-OHT/LNA-scr samples, and the EtOH/ LNA-miR-34a versus EtOH/LNA-scr samples), and unified the four lists, resulting in 1730 genes (this set was $<20 \%$ of the genes because the four lists had some overlap). Hierarchical clustering was performed using MATLAB, resulting in 15 clusters. List of differential genes and their assignment to clusters are in Supplementary Table S3. Functional enrichment analysis was carried out using the DAVID website. ${ }^{25}$ Promoter analysis was carried out using AMADEUS. ${ }^{27}$

Acknowledgements. We thank Dr. Robert A Hipskind for kindly providing us with the ELK1 expression construct and Dr. Martin Bushell for kindly providing us

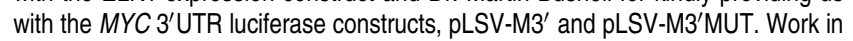
the authors' laboratories has been supported by the EC FP7 funding (ONCOMIRS, grant agreement number 201102. The commission is not liable for any use that may be made of the information herein), the Vilhelm Pedersen and Hustrus Foundation, the Danish National Research Foundation, the Danish Medical Research Council, the Danish Cancer Society and the Association for International Cancer Research. This publication reflects only the authors' views.

1. d'Adda di Fagagna F, Reaper PM, Clay-Farrace L, Fiegler H, Carr P, Von Zglinicki T et al. A DNA damage checkpoint response in telomere-initiated senescence. Nature 2003; 426: 194-198.

2. Herbig U, Jobling WA, Chen BP, Chen DJ, Sedivy JM. Telomere shortening triggers senescence of human cells through a pathway involving ATM, p53, and p21(CIP1), but not p16(INK4a). Mol Cell 2004; 14: 501-513.

3. Takai $H$, Smogorzewska $A$, de Lange T. DNA damage foci at dysfunctional telomeres. Curr Biol 2003; 13: 1549-1556.

4. Serrano M, Lin AW, McCurrach ME, Beach D, Lowe SW. Oncogenic ras provokes premature cell senescence associated with accumulation of p53 and p16INK4a. Cell 1997; 88: 593-602.

5. Palmero I, Pantoja C, Serrano M. p19ARF links the tumour suppressor p53 to Ras. Nature 1998; 395: 125-126. 
6. Courtois-Cox S, Genther Williams SM, Reczek EE, Johnson BW, McGillicuddy LT, Johannessen $\mathrm{CM}$ et al. A negative feedback signaling network underlies oncogeneinduced senescence. Cancer Cell 2006; 10: 459-472.

7. Di Micco R, Fumagalli M, d'Adda di Fagagna F. Breaking news: high-speed race ends in arrest - how oncogenes induce senescence. Trends Cell Biol 2007; 17: 529-536.

8. Courtois-Cox S, Jones SL, Cichowski K. Many roads lead to oncogene-induced senescence. Oncogene 2008; 27: 2801-2809.

9. Mooi WJ, Peeper DS. Oncogene-induced cell senescence - halting on the road to cancer N Engl J Med 2006; 355: 1037-1046.

10. Olsen CL, Gardie B, Yaswen P, Stampfer MR. Raf-1-induced growth arrest in human mammary epithelial cells is p16-independent and is overcome in immortal cells during conversion. Oncogene 2002; 21: 6328-6339.

11. Bushati N, Cohen SM. MicroRNA functions. Annu Rev Cell Dev Biol 2007; 23: 175-205.

12. Cho WC. OncomiRs: the discovery and progress of microRNAs in cancers. Mol Cance 2007; 6: 60.

13. Bommer GT, Gerin I, Feng Y, Kaczorowski AJ, Kuick R, Love RE et al. p53-mediated activation of miRNA34 candidate tumor-suppressor genes. Curr Biol 2007: 17: 1298-1307.

14. Chang TC, Wentzel EA, Kent OA, Ramachandran K, Mullendore M, Lee KH et al. Transactivation of miR-34a by p53 broadly influences gene expression and promotes apoptosis. Mol Cell 2007; 26: 745-752.

15. Corney DC, Flesken-Nikitin A, Godwin AK, Wang W, Nikitin AY. MicroRNA-34b and MicroRNA-34c are targets of p53 and cooperate in control of cell proliferation and adhesion-independent growth. Cancer Res 2007; 67: 8433-8438.

16. Raver-Shapira N, Marciano E, Meiri E, Spector Y, Rosenfeld N, Moskovits N et al. Transcriptional activation of miR-34a contributes to p53-mediated apoptosis. Mol Cell 2007; 26: 731-743.

17. He L, He X, Lim LP, de Stanchina E, Xuan Z, Liang Y et al. A microRNA component of the p53 tumour suppressor network. Nature 2007; 447: 1130-1134.

18. Tarasov V, Jung P, Verdoodt B, Lodygin D, Epanchintsev A, Menssen A et al. Differentia regulation of microRNAs by p53 revealed by massively parallel sequencing: miR-34a is a p53 target that induces apoptosis and G1-arrest. Cell Cycle 2007; 6: 1586-1593.

19. Pritchard CA, Samuels ML, Bosch E, McMahon M. Conditionally oncogenic forms of the A-Raf and B-Raf protein kinases display different biological and biochemical properties in NIH 3T3 cells. Mol Cell Biol 1995; 15: 6430-6442.

20. Zhu J, Woods D, McMahon M, Bishop JM. Senescence of human fibroblasts induced by oncogenic Raf. Genes Dev 1998; 12: 2997-3007.

21. Tazawa H, Tsuchiya N, Izumiya M, Nakagama H. Tumor-suppressive miR-34a induces senescence-like growth arrest through modulation of the E2F pathway in human colon cancer cells. Proc Natl Acad Sci USA 2007; 104: 15472-15477.

22. Shaulian $E$, Zauberman A, Ginsberg D, Oren M. Identification of a minimal transforming domain of p53: negative dominance through abrogation of sequence-specific DNA binding Mol Cell Biol 1992; 12: 5581-5592.

23. Chang F, Steelman LS, Lee JT, Shelton JG, Navolanic PM, Blalock WL et al. Signal transduction mediated by the Ras/Raf/MEK/ERK pathway from cytokine receptors to transcription factors: potential targeting for therapeutic intervention. Leukemia 2003; 17: 1263-1293.

24. Loots GG, Ovcharenko I, Pachter L, Dubchak I, Rubin EM. rVista for comparative sequence-based discovery of functional transcription factor binding sites. Genome Res 2002; 12: 832-839.

25. Dennis Jr G, Sherman BT, Hosack DA, Yang J, Gao W, Lane HC et al. DAVID: Database for Annotation, Visualization, and Integrated Discovery. Genome Biol 2003; 4: P3.
26. Sun F, Fu H, Liu Q, Tie Y, Zhu J, Xing R et al. Downregulation of CCND1 and CDK6 by miR-34a induces cell cycle arrest. FEBS Lett 2008; 582: 1564-1568.

27. Linhart C, Halperin Y, Shamir R. Transcription factor and microRNA motif discovery: the Amadeus platform and a compendium of metazoan target sets. Genome Res 2008; 18: 1180-1189.

28. Orom UA, Nielsen FC, Lund AH. MicroRNA-10a binds the $5^{\prime}$ UTR of ribosomal protein mRNAs and enhances their translation. Mol Cell 2008; 30: 460-471.

29. Welch $C$, Chen $Y$, Stallings RL. MicroRNA-34a functions as a potential tumor suppressor by inducing apoptosis in neuroblastoma cells. Oncogene 2007; 26: 5017-5022.

30. Bagchi A, Mills AA. The quest for the 1 p36 tumor suppressor. Cancer Res 2008; 68 : 2551-2556.

31. Lodygin D, Tarasov V, Epanchintsev A, Berking C, Knyazeva T, Korner H et al. Inactivation of miR-34a by aberrant CpG methylation in multiple types of cancer. Cell Cycle 2008; 7: 2591-2600.

32. Ohtani N, Zebedee Z, Huot TJ, Stinson JA, Sugimoto M, Ohashi Y et al. Opposing effects of Ets and Id proteins on p16INK4a expression during cellular senescence. Nature 2001; 409: 1067-1070.

33. Kumamoto K, Spillare EA, Fujita K, Horikawa I, Yamashita T, Appella E et al. Nutlin-3a activates p53 to both down-regulate inhibitor of growth 2 and up-regulate mir-34a, mir-34b, and mir-34c expression, and induce senescence. Cancer Res 2008; 68: 3193-3203.

34. Frankel LB, Christoffersen NR, Jacobsen A, Lindow M, Krogh A, Lund AH. Programmed cell death 4 (PDCD4) is an important functional target of the microRNA miR-21 in breast cancer cells. J Biol Chem 2008; 283: 1026-1033.

35. Krutzfeldt J, Rajewsky N, Braich R, Rajeev KG, Tuschl T, Manoharan M et al. Silencing of microRNAs in vivo with 'antagomirs'. Nature 2005; 438: 685-689.

36. Raver-Shapira N, Oren M. Tiny actors, great roles: microRNAs in p53's service. Cell Cycle 2007; 6: 2656-2661.

37. Wei JS, Song YK, Durinck S, Chen QR, Cheuk AT, Tsang P et al. The MYCN oncogene is a direct target of miR-34a. Oncogene 2008; 27: 5204-5213.

38. Leucci $E$, Cocco M, Onnis A, De Falco G, van Cleef $P$, Bellan $C$ et al. MYC translocationnegative classical Burkitt lymphoma cases: an alternative pathogenetic mechanism involving miRNA deregulation. J Pathol 2008; 216: 440-450.

39. Kong YW, Cannell IG, de Moor CH, Hill K, Garside PG, Hamilton TL et al. The mechanism of micro-RNA-mediated translation repression is determined by the promoter of the target gene. Proc Natl Acad Sci USA 2008; 105: 8866-8871.

40. Zhuang D, Mannava S, Grachtchouk V, Tang WH, Patil S, Wawrzyniak JA et al. C-MYC overexpression is required for continuous suppression of oncogene-induced senescence in melanoma cells. Oncogene 2008; 27: 6623-6634.

41. Wu CH, van Riggelen J, Yetil A, Fan AC, Bachireddy P, Felsher DW. Cellular senescence is an important mechanism of tumor regression upon c-Myc inactivation. Proc Natl Acad Sci USA 2007; 104: 13028-13033.

42. Guney I, Wu S, Sedivy JM. Reduced c-Myc signaling triggers telomere-independent senescence by regulating Bmi-1 and p16(INK4a). Proc Natl Acad Sci USA 2006; 103: 3645-3650.

43. Littlewood TD, Hancock DC, Danielian PS, Parker MG, Evan Gl. A modified oestrogen receptor ligand-binding domain as an improved switch for the regulation of heterologous proteins. Nucleic Acids Res 1995; 23: 1686-1690.

44. Fujita N, Wade PA. Use of bifunctional cross-linking reagents in mapping genomic distribution of chromatin remodeling complexes. Methods 2004; 33: 81-85.

Supplementary Information accompanies the paper on Cell Death and Differentiation website (http://www.nature.com/cdd) 